\title{
Cervical Epidural Anesthesia for Carotid Endarterectomy
}

\author{
M Alauddin', B M M Choudhury ${ }^{1}$, AK Beg1, SA N Alam², AYF E Chowdhury ${ }^{1}$ \\ ${ }^{1}$ Department of Anaesthesiology, NICVD, Dhaka. ${ }^{2}$ Department of Vascular Surgery, NICVD, Dhaka
}

\begin{abstract}
:
Keywords : Cervical epidural Anaesthesia, Carotid Endarterectomy, Monitoring of The successful anaesthetic management using a cervical epidural technique is reported in patients undergoing carotid artery surgery. Adequate analgesia is obtained and the adequacy of cerebral blood flow is easily judged by the patient's state of consciousness. Cervical epidural anaesthesia could be a safe and reasonable technique for the management of patients who need carotid artery surgery. ${ }^{1}$

A 54 years old man of A.S.A (American Society of Anesthesiologists) grade- II underwent carotid endarterectomy under Cervical Epidural Anaesthesia (CEA) at $C_{7}-T_{1}$ level using a mixture of 0.5\% Lidocaine, $0.25 \%$ Bupivacaine and Fentanyl citrate. Standard peroperative monitoring including invasive arterial blood pressure and arterial blood gas analysis was done.
\end{abstract}

(Cardiovasc. j. 2010; 2(2) : 256-257)

\section{Case Report:}

A 54 years old pleasant gentleman weighing about $60 \mathrm{Kg}$ was admitted in NICVD with the complaint of transient ischaemic attack (T I A). He was a diagnosed case of left internal carotid artery (ICA) atherosclerotic lesion. He was hypertensive, non diabetic and non asthmatic of A.S.A grade II and scheduled for carotid endarterectomy under CEA. He was duly informed about the anaesthetic procedure during preanaesthtic check up. Patient was premedicated with tablet midazolam $(7.5 \mathrm{mg})$ 1 hour before arrival at OT.

An 18 G epidural catheter was introduced aseptically and uneventfully at $\mathrm{C}_{7}-\mathrm{T}_{1}$ intervertebtal space with patient in sitting position through midline approach using loss of resistance technique. Anaesthesia was induced with a mixture of $0.5 \%$ Lidocaine $(5 \mathrm{ml}) .0 .25 \%$ Bupivacaine $(5 \mathrm{ml})$ and Fentanyl citrate $(50 \mu \mathrm{g})$. After 20 minutes the onset of anaesthesia was completed and pin-prick pain sensation was abolished, Monitoring of $\mathrm{Spo}_{2}$, ECG, Respiration, Heart rate, Urine out put, Intraarterial blood pressure and ABG analysis etc were done. The patient received Oxygen @ 4L/ min via a nasal cannula.

Surgery was conducted smoothly and uneventfully under CEA with good analgesia. Patient was awake during surgery. Total duration of surgery was 2 hours and one additional top up dose (1/3 $3^{\text {rd }}$ of initial bolus) was given after 1 and $1 /$ 2 hour with intermittent propofol infusion @ 25$50 \mu \mathrm{g} / \mathrm{kg} / \mathrm{min}$. Post operative recovery was smooth. Patient was started on a liquid diet and allowed to mobilize 4 hours after surgery. Post operative analgesia was maintained with $0.125 \%$ Bupivacaine (4 ml) with Fentanyl citrate $2 \mu \mathrm{g} / \mathrm{ml}$ through epidural catheter 6 hourly or earlier if the patient complains of pain. No other rescue analgesia was required.

\section{Discussion:}

Carotid endarterectomy can be performed under general or regional anaesthesia. Regional anaesthesia may be either cervical plexus block or cervical epidural anaesthsia. Regional anaesthesia is more cost-effective, given that less intensive care and shorter hospital stays are required. ${ }^{2} \mathrm{GA}$ is the conventional method, CEA is practiced less often because of the fear of potential complication. Cervical plexus block is an alternative for CEA but this may be incomplete, surgery cannot be prolonged, and post operative analgesia is not possible. Monitoring of cerebral function is difficult under GA. By contrast, continuous monitoring of awareness and neurological deficit and hence adequacy of cerebral perfusion is possible under regional anaesthesia. ${ }^{3}$ This however can become a disadvantage if the patient develops cerebral ischaemia which may lead to disorientation, 
inadequate ventilation and difficult to perform surgery due to unfavorable conditions. This may require conversion to GA but endotracheal intubation in this setting prove difficult. Advantages of GA include control of airway, a quiet operative field and the ability to maximize cerebral perfusion if ischaemia develops. So, ultimately the choice of anaesthetic technique is based on patient's suitability, preference of the surgeon and anaesthetist's experience and expertise.

\section{Conclusion:}

CEA is a safe \& effective alternative to GA. It was preferred by our patient as well as surgical team because of its safety, lower costs, ability to assess neurological deficit, early ambulation, oral feeding, better post operative analgesia and reduced perioperative morbidity. More work in this subject will be useful for optimum surgical and anaesthetic outcome.

\section{References:}

1. M.Kainuma, Y.Shimada, M.Matsuura. Cervical Epidural Anaesthesia in Carotid Artery Surgery. Journal of the Association of Anaesthetists of Great Britain and Ireland 2007; 41(10):1020-1023.

2. Lehot.J.J, Durand P.G. . Anaesthesia for Carotid Endarterectomy. Revista espaòola de anestesiologia y reanimación 2001; 48(10):499-507.

3. Pluskwa F, Bonnet F, Touboul C, Szekely B, Roujas F, Becquemin JP. Carotid Endarterectomy under Cervical Epidural Anaesthesia; Analysis of neurological manifestations. Ann Fr Anesth Reanim 1988; 7(1):36-41. 